\title{
Trabalhonecessário
}

Issn: 1808 - 799X

ano 13 , número $20-2015$

\section{O PERCURSO HISTÓRICO DO GT TRABALHO E EDUCAÇÃO - UM EXERCÍCIO DE INTERPRETAÇÃO}

Maria Ciavatta $^{1}$

\section{Resumo}

Traçamos as linhas gerais do percurso do GT Trabalho e Educação a partir de três categorias: pensamento crítico, trabalho e educação e historicidade. É um trabalho de meta-teoria, no sentido de que realiza uma análise teórica sobre o que já foi tratado teoricamente por outros autores. O GT TE tem por base o referencial marxista, a partir da crítica à economia política. Os trabalhos discutidos no GT situam-se no campo do pensamento crítico. Salvo poucos trabalhos, o tratamento histórico das questões não está explícito, mas a historicidade insinua-se na materialidade do espaço-tempo das pesquisas.

Palavras-chave: trabalho e educação - pensamento crítico - historicidade

\begin{abstract}
We traced the outline of the GT Work and Education course from three categories: critical thinking, work and education and historicity. It is a meta- work, in the sense that performs an analysis regarding what has been theoretically treated by other authors. The TE GT is marked by the marxist framework, based on the critique of political economy. The papers discussed in GT are in the field of critical thinking. With exception of a few papers, the historical treatment of the issues is not explicit, but the historicity insinuates itself in the materiality of the research space-time
\end{abstract}

\footnotetext{
1 Licenciada em Filosofia, Doutora em Ciências Humanas (Educação), PUC-RJ; Pós-doutorado em Sociologia do Trabalho em El Colegio de México e na Università di Bologna, Itália; Professora Titular de Trabalho e Educação, associada ao Programa de Pós-graduação em Educação da Universidade Federal Fluminense (UFF). Pesquisadora do CNPq. mciavatta@terra.com.br
} 


\section{Trabalhonecessário}

Issn: 1808 - 799X

ano 13, número $20-2015$

Key-words: work and education - critical thinking - history

"O pensamento crítico tem recebido nomes e sobrenomes, mas em sua produção não vejo escolas nem discípulos, salvo umas vontades subversivas"

(Edelberto Torres-Rivas)

\section{Introdução}

O GT Trabalho e Educação tem, aproximadamente, trinta anos de existência e uma trajetória constante na ANPEd. O desenvolvimento do tema, o percurso do GT TE, supõe o trabalho de uma equipe de pesquisa. Dentro do espaço-tempo que tivemos para sua elaboração, pudemos fazer apenas um exercício que permitiu subsidiar estudos futuros de maior abrangência e profundidade, sem ter a possibilidade de examinar os textos originais apresentados no GT, de modo a trabalhar diretamente sobre a palavra dos autores.

No Brasil, as políticas neoliberais que acompanharam a reestruturação produtiva a partir dos anos 1990 trouxeram ainda mais mal-estar às tradicionais condições de trabalho e de vida de milhões de trabalhadores e evidenciaram posições políticas divergentes entre os cientistas sociais e militantes que deram forma avançada à recuperação da democracia ao final da Ditadura. Divisões político-partidárias e de interpretação dos problemas objetivos da sociedade criaram novos desafios teóricos e práticos.

O GT Trabalho e Educação (GT TE) não foi imune a essas circunstâncias. Mas resgatar seus meandros e suas expressões nas Reuniões Anuais da ANPEd requer uma atividade maior de pesquisa.

Neste texto, sirvo-me de alguns trabalhos, entre os quais, dois elaborados com minha participação. Em ordem cronológica: o texto de Acácia Kuenzer 


\section{Trabalhonecessário}

Issn: $1808-799 X$

ano 13, número $20-2015$

(1987); a seguir, a análise de Eunice Trein e Iracy Picanço (1995); a entrevista de Eunice Trein (1996); o artigo de Eneida Oto Shiroma e Roselane Fátima Campos (1997); o artigo de Lucília Machado (2005); a tese de doutorado de Alexandre Maia do Bonfim (2006); os artigos de Eunice Trein e Maria Ciavatta (2003 e 2009). Resta, portanto, muito por fazer para traçar o percurso do GT TE, até esta data (agosto de 2014).

De alguma forma, este é um trabalho de metateoria, no sentido de que realiza uma análise teórica sobre o que já foi tratado teoricamente por outros autores. Para tanto, devemos explicitar os conceitos (Ciavatta, 2012). Destacamos, para os fins deste estudo, as categorias: (i) pensamento crítico, (ii) trabalho e educação e (iii) historicidade, para tentar traçar o percurso do GT.

\section{O GT TE e o pensamento crítico}

O texto tomado como epígrafe sintetiza a imprecisão na formulação do conceito de pensamento crítico e, ao mesmo tempo, sinaliza seu conteúdo de ação, "vontades subversivas". "A força subversiva se reconhece pela capacidade para alterar, mudar, desordenar", diz Torres-Rivas (op. cit., p. 20). O contexto da expressão, neste autor e em outros cientistas sociais latino-americanos, é o do marxismo; a concepção teórica que o qualifica é o materialismo histórico como teoria do conhecimento e como teoria da ação política.

Embora a ideia de critica seja de uso corrente no campo dos autores marxistas, muitos dos quais do campo TE, o termo pensamento crítico tem sido objeto mais comum de discussão nos países sul-americanos de língua espanhola do que no Brasil. Partimos dessa realidade para uma breve exposição sobre seu significado, segundo alguns desses autores, e pela presença dos conceitos afins com o pensamento crítico, nos trabalhos sobre o GT TE. 


\section{Trabalhonecessário}

Issn: $1808-799 X$

ano 13, número $20-2015$

Temos por hipótese que, embora o termo não seja de uso corrente no GT, suas posições são confluentes com a parte substantiva do pensamento crítico latino-americano. As fontes de estudo aqui utilizadas devem nos dar algumas indicações sobre as categorias, os conceitos e as questões tratadas como pensamento crítico no GT TE.

O que se entende por pensamento crítico? Diante da sucessão de crises em que o mundo se defronta neste século, em 2008 o Conselho Latino-americano de Ciências Sociais (CLACSO) solicitou a alguns pensadores atuais que respondessem se é possível falar de uma tradição do pensamento crítico latinoamericano e como ele se caracteriza em termos de métodos de análise e de temáticas presentes. O objetivo foi fazer um balanço das transformações ocorridas no Continente e, após a desmobilização política trazida pelo neoliberalismo, compreender a recuperação do pensamento crítico à luz das iniciativas políticas em curso. ${ }^{2}$

A Revista Crítica y Emancipación traz uma enquete com uma entrevista sobre pensamento crítico e artigos sobre problemas específicos de nossa contemporaneidade, onde as respostas destacam os temas dependência, marxismo, revolução e democracia e as situações concretas de lutas políticas na América Latina (Altamirano et al., 2009, p.14, grifos nossos). ${ }^{3}$ Nesta oportunidade, vamos nos limitar à compreensão das principais categorias analíticas trazidas por dois autores, ${ }^{4}$ que responderam à questão: "É possível falar de uma tradição de pensamento crítico latino-americano?" (Altamirano, ibid.; Torres-Rivas, ibid.).

\footnotetext{
${ }^{2}$ Para E. Sader, o pensamento crítico latino-americano tem reivindicado nossa trajetória histórica frente aos esquemas eurocêntricos, assim como fortalecer nossa identidade, questionando o pensamento conservador criado pelas potências centrais do capitalismo. Textos de Ruy Mauro Marini, Agustín Cueva, Álvaro García Linera, Celso Furtado, Aldo Ferrer, Maria da Conceição Tavares, Pablo Gonzáles Casanova, José Carlos Mariátegui. Disponível em http://livrariapopular.blogspot.com.br/2010/03/cadernos-de-pensamento-critico-latino.html Acesso em 05-102014.

${ }^{3}$ Néstor Kohan (2006) que desenvolve a gênese do pensamento crítico a partir da Revolução Cubana e da cultura de massas dos anos 1960.

${ }^{4}$ Esta reflexão é parte de um projeto de pesquisa (Ciavatta, 2012).
}

TrabalhoNecessário - www.uff.br/trabalhonecessario; Ano 13, № 20/2015. 


\section{Trabalhonecessário}

Issn: $1808-799 X$

ano 13, número $20-2015$

O termo crise e seu adjetivo crítico tem sido alvo de banalização no mundo atual. Seja porque são tantas as crises, são tantos os momentos críticos, seja porque, consequentemente, seus significados perderam a força social de mobilizar as pessoas. No entanto, a atribuição de situação crítica ou de crise envolve ruptura com alguma forma de ser, tensão, fase difícil na evolução dos acontecimentos, das ideias. Uma crise histórica pode ser um momento de ruptura, perigoso, decisivo, que afeta a vida de pessoas, grupos e classes na sociedade.

O pensamento crítico latino-americano provém da reflexão levada adiante por pensadores do Continente em posição de ruptura com as formas sociais coloniais e escravistas nos séculos passados e com todas as formas de dominação capitalista passadas e presentes. Uma característica básica do sentido de crítica e, portanto, do pensamento crítico, no referencial marxista, é ir além da aparência da realidade, buscar apreender o real nas relações sociais que o constituem, ocultas à primeira vista, o real como concreto, pensado como "síntese de múltiplas determinações" (Marx, 1977, p.229).

$\mathrm{Na}$ base deste pensamento estão os autores que desvelaram a exploração do trabalho e a desumanização dos trabalhadores, elaboraram um pensamento alternativo de transformação dessas mesmas condições e

(...) começaram a reinterpretar nossa história à luz de suas particularidades, conforme o sistema internacional foi nos integrando - mediante os conhecidos métodos da acumulação primitiva, incluindo a colonização e a escravidão, ao mercado mundial (Sader, 2009, p.12).

Juan Carlos Mariátegui e José Martí foram os primeiros expoentes desse pensamento. No século passado, a CEPAL (Comisión Económica para la América Latina) e os intelectuais ${ }^{5}$ que elaboraram a teoria da dependência ou sua melhor expressão, a teoria do capitalismo dependente, destacaram as relações centroperiferia que dão forma às condições de submissão econômica, política e social

5 Os antecedentes da noção de dependência estão em Sergio Bagu (historiador mexicano) e em Caio Prado Jr. (historiador e geógrafo brasileiro) (Torres-Rivas, 2009b., p.52).

TrabalhoNecessário - www.uff.br/trabalhonecessario; Ano 13, № 20/2015. 


\section{Trabalhonecessário}

Issn: $1808-799 X$

ano 13, número $20-2015$

dos nossos países aos países de capitalismo central. Theotonio dos Santos, Vânia Bambirra, Rui Mauro Marini, Agustin Cueva, Florestan Fernandes são seus principais representantes.

Os anos passados no Chile, depois da vitória da Unidade Popular com Salvador Allende, foram os de formação do pensamento latino-americano sobre marxismo, dependência, revolução e democracia (Torres-Rivas, op. cit., p.56). ${ }^{6}$ Carlos Altamirano et al. (2009) entende que a ideia e a expressão pensamento crítico são modernas e indicam um questionamento à ordem estabelecida a partir de certos valores que contemplam a verdade e a justiça. É um pensamento que se opõe a todo tipo de conformismo e às ideologias dos setores dominantes.

Duas temáticas têm estado presente no discurso crítico assim entendido: a opressão social que pode estar combinada à opressão racial e as condições de dependência dos países latino-americanos. Estão na sua base as diversas correntes do pensamento social moderno, quais sejam, 0 anarquismo, 0 socialismo e a ação política decorrentes de conflitos e movimentos coletivos. ${ }^{7}$

No caso do Brasil, essa perspectiva tem sua atuação dificultada pelos rumos políticos autoritários e neoliberais. Presenciamos a ascensão dos movimentos sociais e a elaboração teórica de crítica ao neoliberalismo implantado no país a partir dos anos 1990 -, ao imperialismo e a suas novas formas de dominação, a todas as situações de subordinação ao capitalismo dependente. No entanto, a partir dos anos 2000, pari passu com o desenvolvimentismo e políticas assistenciais em grande escala, perderam-se 0 ideário e a incipiente organização política rumo a transformações estruturais. A ofensiva das forças conservadoras e a submissão consentida ao capital dos

\footnotetext{
6 O sociólogo guatemalteco assim se expressa: "No Chile, com Theotonio dos Santos e Vania, estudei o Capital, não na Guatemala. Deixei de ser militante, mas me tornei marxista. (...)" (Ibid., p.56).

7 "No final do século XIX começo do século $X X$, às vezes vem associado ao liberalismo, principalmente, como denúncia das ditaduras, e, desde a década de 1920, a crítica antiimperialista conjugou o pensamento de esquerda e temas nacionalistas". (Altamirano, ibid., pp.1415).
} 


\section{Trabalhonecessário}

Issn: 1808 - 799X

ano 13 , número $20-2015$

períodos, Cardoso, Lula e Dilma, trouxeram a fragmentação política da esquerda e novos conflitos no plano do pensamento crítico.

Em linhas gerais, as atividades do GT TE confirmam nossa hipótese inicial de que suas posições teóricas e políticas são confluentes com a parte substantiva do pensamento crítico latino-americano. Os estudos elaborados sobre o GT, mencionados anteriormente, com base no marxismo, sinalizam a predominância da oposição às formas vigentes de dominação. Expressam, também, a análise da contradição capital e trabalho como base fundamental das análises da relação trabalho e educação, a visão histórica da sociedade, da produção e das classes sociais, o questionamento das políticas educacionais, principalmente, de educação da população trabalhadora.

$O$ aprofundamento do pensamento crítico no GT TE tem dois marcos fundamentais que se expressam na mudança do nome do Grupo, de GT "Educação e Trabalho" para "Trabalho e Educação". O primeiro marco é o curso de Doutorado em Educação na PUC-RJ no início da década de 1980, que, sob a orientação do Prof. Dermeval Saviani, formou um primeiro grupo de pesquisadores que delinearam o percurso do campo TE: Acácia Kuenzer, Gaudêncio Frigotto, Lucília Machado, Paolo Nosella, Celso Ferretti. Também se tornaram referência na área Miguel Arroyo e Iracy Picanço.

O outro marco da mudança de nome e adoção da perspectiva crítica com base no materialismo histórico ocorreu na segunda metade dos anos 1980, no momento em que a sociedade se organizava nos novos espaços criados pelo fim oficial da Ditadura Civil-militar (1964-1985). Foi o Encontro de Pesquisadores promovido por Acácia Kuenzer que assumiu a Coordenação de Educação e Trabalho no CNPq, em fevereiro de 1986, com a responsabilidade de elaborar um programa de pesquisa para a área. Depois de quatro dias de trabalho, o grupo elaborou o programa de pesquisa e justificou a mudança do nome do GT para Trabalho e Educação, o que refletia "mais do que uma mudança semântica, uma concepção teórica fundamentada em uma opção política". Alertava-se ainda para 


\section{Trabalhonecessário}

Issn: $1808-799 X$

ano 13, número $20-2015$

"a manipulação dos conceitos gerais como se fossem uma realidade com substantividade própria, independente de tempo e lugar" (ibid., p.93, grifos nossos).

Resta-nos ainda realizar o exercício de buscar, nos trabalhos de síntese analítica dos textos apresentados no GT, expressões teóricas e empíricas ou de conteúdo das categorias, conceitos e temáticas que apontam na direção do pensamento crítico. Cabe observar que esta concepção, nos termos dos cientistas sociais, pauta-se pelas grandes questões da sociedade que, em alguns casos, inclui a educação, principalmente, a universidade. Já o pensamento crítico expresso pelo GT está sempre ancorado na teoria marxista e nas questões educacionais, de modo especial, no modo de produção capitalista, nas relações de trabalho, na educação dos trabalhadores e nas políticas educacionais (educação profissional, técnica e tecnológica, sua relação com o ensino médio e a universidade e, mais recentemente, educação de jovens e adultos).

\section{Trabalho e educação: um binômio em busca de seu significado}

No tempo da criação da ANPEd, final dos anos 1970, os grupos de pesquisa se organizaram por disciplina (a exemplo de História da Educação), por nível de ensino (a exemplo de Ensino Médio), por temas (a exemplo de Currículo) ou por temas mistos (a exemplo de Política de Educação Superior). No caso do GT TE, a junção de dois nomes, inicialmente, Educação e Trabalho, expressa a preocupação com a teoria e com a ação na sociedade.

A relação entre o Trabalho e a Educação é um tema tratado desde o século passado, tanto pela economia política burguesa quanto pela marxista. No Brasil, a ideia aparece com a redemocratização do país, em curso no final dos anos 1970 e início dos anos 1980. Era a tentativa de construção de um novo projeto hegemônico, assim como a afirmação de alguns cursos de pós-graduação em 


\section{Trabalhonecessário}

Issn: $1808-799 X$

ano 13 , número $20-2015$

educação rumo a uma visão crítica e dialética. Sem o uso corrente do termo pensamento crítico, o tema trabalho e educação aparece vinculado ao materialismo histórico, às análises marxistas, à superação do autoritarismo e o comprometimento com as lutas dos trabalhadores por maior participação política e econômica (Trein e Ciavatta, 2003, p.141).

Com a participação direta de alguns pesquisadores do campo TE, reunidos no Fórum Nacional em Defesa da Escola Pública, em meados dos 1980, os educadores, intelectuais, militantes de várias organizações acadêmico-científicas e de movimentos sociais reuniram esforços para a elaboração do capítulo sobre a educação na nova Constituição, aprovada em 1988, e para a nova Lei de Diretrizes e Bases da Educação Nacional. Discutiu-se muito a questão da educação politécnica, da escola unitária e do trabalho como princípio educativo. Renovou-se a crítica da profissionalização compulsória (segundo a Lei $\mathrm{n} . \stackrel{0}{ }$ $5.692 / 1971)$. A defesa da introdução do trabalho na educação levava à questão de pensar o trabalho além da alienação das formas mercantilizadas do trabalho, 0 que significa a educação do ser humano em toda a sua potencialidade. ${ }^{8}$

Pelas informações que temos, Trabalho e Educação, como grupo de pesquisa e como subárea de conhecimento, é uma inovação brasileira. ${ }^{9}$ Salvo a importante vinculação do trabalho à educação, feita por Marx, anteriormente, predominavam os estudos ligados à economia da educação, à formação profissional e técnica e a área da Sociologia do Trabalho. No campo educacional, sob o título Trabalho e Educação, as pesquisas passaram a buscar "a compreensão dos processos pedagógicos escolares e não escolares a partir do mundo do trabalho, tomando-se o método da economia política como diretriz para a construção do conhecimento" (apud Kuenzer, 1998, p.55). Tentava-se superar os limites herdados do enfoque restrito à formação profissional para 0

\footnotetext{
8 Marx (entre outros, 1979), Lukács (1978), Manacorda (1990), Saviani (1989) foram os principais mestres que alimentaram os debates sobre o tema.

$9 \mathrm{Na}$ última década, grupos de estudos e pesquisas de outros países latino-americanos começaram a se autodenominar Educación y Trabajo (a exemplo da Argentina, Uruguai, Colômbia).
}

TrabalhoNecessário - www.uff.br/trabalhonecessario; Ano 13, № 20/2015. 


\section{Trabalhonecessário}

Issn: $1808-799 X$

ano 13 , número $20-2015$

desenvolvimento econômico, à "Teoria do capital humano", ao tecnicismo, às teorias reprodutivistas (Ciavatta Franco, 1990). Subjacentes às discussões sobre a profissionalização, a preparação para o trabalho e a educação do trabalhador, estavam o trabalho como princípio educativo e a educação politécnica (Trein; Ciavatta, ibid.).

Consolidou-se a ideia de que a relação trabalho e educação se enraíza nas condições de vida e de trabalho ou de produção da existência na sociedade em que vivemos, no caso, o Brasil, uma sociedade de classes baseada na divisão social e técnica do trabalho em condições de extrema desigualdade social. Sua base é a apropriação privada dos produtos do trabalho coletivo, expresso na riqueza social concentrada em bens e serviços (educação, cultura, ciência, tecnologia, arte, comunicação etc.), distribuídos de forma desigual entre as classes sociais. A compreensão histórica das políticas públicas implica, também, o conhecimento de como elas são representadas ao nível do real, dos discursos e das leis da educação e do trabalho.

Tanto o trabalho, quanto a educação ocorrem em uma dupla perspectiva. $O$ trabalho tem um sentido ontológico, de atividade histórica, criativa e fundamental da vida humana; tem formas históricas, penosas, socialmente produzidas, particularmente, no espaço da produção capitalista (Lukács, 1978).

A educação que se pretende oferecer aos jovens, concebendo o trabalho como princípio educativo, tem, como critério fundamental, ser uma formação humanizadora. De ter, por base, valores e práticas ética e culturalmente elevadas, com base nas ciências, nas tecnologias, nas letras, nas artes, na valorização do trabalhador e de uma vida digna para todos, o que significa, também, com uma visão política da própria realidade. Mas, salvo exceções, a educação profissional, particularmente, ocorre em formas pragmáticas a serviço de interesses e de valores do mercado, não convergentes com o seu sentido fundamental de formação humana, potencializadora do desenvolvimento pleno do ser humano. 


\section{Trabalhonecessário}

Issn: 1808 - 799X

ano 13 , número $20-2015$

Diferente dos animais que agem guiados pelo instinto, de forma quase imediata, o ser humano age através de mediações, de recursos materiais e espirituais que ele implementa para alcançar os fins desejados. Do ponto de vista educacional, significa opor-se a reduzir o ensino médio à educação profissional como preparação funcional ao mercado de trabalho.

Desde os primeiros estudos realizados sobre os trabalhos apresentados no GT, sob o referencial do materialismo histórico, são muitos os temas desenvolvidos. Kuenzer (1987) justifica seu trabalho como "um balanço do conhecimento que tem sido produzido nessa área" (pp.5-6). Busca identificar temas de pesquisa emergentes e tenta avançar nas questões postas pela sociedade, em um momento em que se buscava a redemocratização do país, ao final da Ditadura Civil-militar [1964-1895], e em que a cidadania não se realizava sequer segundo os preceitos liberais ${ }^{10}$.

No primeiro trabalho realizado sobre o GT TE (Kuenzer, 1987) já está presente a preocupação com o referencial teórico com base no materialismo histórico e em sua apropriação para os fenômenos do campo trabalho e educação. Logo no início, destacam-se algumas questões: "Não raramente, confunde-se a relação entre educação e trabalho com a relação entre escola e trabalho. (...)", uma "falácia", nas palavras da autora. "O saber não é produzido na escola, mas no interior das relações em seu conjunto (...) o trabalho é a categoria que se constitui no fundamento da produção do conhecimento" (ibid., p.21). Kuenzer (ibidem, p.26) também se detém sobre a distribuição desigual do conhecimento na escola, a divisão do trabalho que desqualifica os trabalhadores e a educação para o trabalho de forma diferenciada, a partir da origem de classe.

A conjuntura dos anos 1980, quando o texto foi escrito, e experiência da autora em pesquisa sobre a "pedagogia da fábrica", que consiste em promover o aprendizado de um conjunto de operações parciais que retira dos trabalhadores a visão do todo e da ciência incorporada nos processos produtivos capitalistas

10 Referimo-nos à cidadania segundo a conquista dos direitos classificados por Marshall (1967): direitos civis, direitos políticos e direitos sociais.

TrabalhoNecessário - www.uff.br/trabalhonecessario; Ano 13, № 20/2015. 


\section{Trabalhonecessário}

Issn: $1808-799 X$

ano 13 , número $20-2015$

(ibidem, pp.26-27), a reestruturação produtiva e as transformações decorrentes das políticas econômicas e sociais de base neoliberal são problemas já identificados que vão vigorar nos anos 1990.

Algumas questões de estudo são levantadas pela autora: os trabalhadores, suas relações de trabalho e sua formação; a constituição do modo de produção capitalista; o pressuposto da unidade teoria e prática; a divisão social e técnica do trabalho; e a dualidade estrutural da sociedade e da educação. ${ }^{11}$ Três grupos de temas elencados pela autora revelam como, desde o início, as principais questões teóricas e empíricas do campo já faziam parte do repertório do GT e do tratamento consistente dos problemas que ele tem mantido.

No primeiro grupo estão alguns pressupostos teóricos, desenvolvidos na forma de tópicos fundamentais para a pesquisa. Em muitos dos temas apontados podemos reconhecer nas teses de doutorado e livros que alguns dos pesquisadores participantes vieram a elaborar, tais como: a "Teoria do capital humano", a abordagem crítico-reprodutivista, a crítica ao reprodutivismo; a produtividade da escola improdutiva, a pedagogia da fábrica, a escola única do trabalho (ibidem, pp.35-90). Detalha, a seguir, as linhas de investigação: Educação e trabalho: teoria e história; Trabalho e educação básica; Profissionalização e trabalho; Trabalho e educação nos movimentos sociais; Educação do trabalhador nas relações sociais de produção (ibidem, pp.95-101), temas presentes até hoje no GT. ${ }^{12}$

Sobre a questão epistemológica do termo Trabalho e Educação, Lucília Machado (2005) publicou um artigo onde trata o binômio como um nome composto e sinaliza, a nosso ver, a unidade intrínseca dos termos como campo

\footnotetext{
11 Kuenzer (op. cit., p.19) distingue o GT TE da Sociologia do Trabalho ou da Sociologia Industrial que estuda o trabalhador a partir do processo produtivo. A área trabalho e educação investiga como "o trabalhador, contraditoriamente, se educa/deseduca no interior das relações de produção, com ou sem a mediação da escola".

12 O sociólogo chileno Hugo Zemelman nos inquiria sobre o estatuto epistemológico do termo "educação e trabalho" como campo de pesquisa ou disciplinar. Não obstante a generalidade abstrata dos termos, o tema "trabalho e educação" consolidou-se como um campo de pesquisa de base marxista e que se ocupa de uma gama de temas que envolvem os dois termos do "binômio", os processos e formas de trabalho e os processos educativos que preparam para o trabalho.
} 


\section{Trabalhonecessário}

Issn: 1808 - 799X

ano 13 , número $20-2015$

de estudos e pesquisas. Seu objetivo foi tratar "Trabalho-Educação como objeto de investigação", síntese que considera um desafio para a pesquisa. Em suas palavras:

Como toda síntese, é preciso proceder ao agrupamento de fatos particulares, de elementos ou noções considerados mais simples para formar um composto, um todo que os abrange e os resume. Mas Trabalho e Educação não são dois objetos de pensamento que possam ser classificados, a rigor, como elementos ou noções simples. Um já contém o outro antes mesmo de colocados em associação. (ibidem, p.129)

Observa que nossa origem, como campo de pesquisa, "deriva das nossas leituras marxianas sobre o processo de hominização" (ibidem, p.130). Reflete que "todo campo científico está obrigado, para ser reconhecido como tal, a reunir seus temas em um marco teórico-metodológico o mais delimitado possível". Reconhece as imprecisões do termo, mas afirma o referencial básico no materialismo histórico. Este implica a abordagem dos objetos de estudo no marco da totalidade social, em suas múltiplas determinações e nas suas mediações históricas. O conhecimento é alcançado por aproximações sucessivas, tanto nos aspectos empíricos, quanto nas sistematizações teóricas (ibidem, p.128, grifos nossos).

O campo teórico e a política perpassam todos os encontros do GT TE. Os movimentos da sociedade adentram nas discussões. Trein e Picanço (1995) registram que "Durante a década de 80 , importante produção foi debatida sobre os temas Trabalho como princípio educativo e Educação politécnica". Foram divulgados, então, os autores internacionais que deram sustentação à proposta de introdução dessa concepção educativa na LDB que viria superar a segmentação das leis da educação herdadas da Ditadura: Mario Manacorda, Mariano Enguita, o Grupo Brighton. Entre os brasileiros que produziram suas obras nesta temática, são citados: Miguel Arroyo, Paolo Nosella, Gaudêncio 


\section{Trabalhonecessário}

Issn: $1808-799 X$

ano 13, número $20-2015$

Frigotto, Lucília Machado, Acácia Kuenzer, Celso Ferretti, Ramon Peña Castro (ibidem, p.89).

Já no contexto das transformações econômicas e sociais trazidas pelas políticas neoliberais dos anos 1990 e início do século XXI, em entrevista, Eunice Trein (1996, p.33) considera que "as mudanças tecnológicas no processo produtivo e suas consequências para a formação dos trabalhadores tem sido uma temática permanente no GT”. Fazendo uma análise da produção do GT de 1996 a 2001, Eunice Trein e Maria Ciavatta (2003, p.141) observam dois grandes eixos temáticos: a reestruturação produtiva e a nova organização do trabalho. No período de pouco mais de dez anos, tinham sido promulgadas a Constituição de 1988 e a nova LDB (Lei n. 9.394/96). Esta última representou muitas perdas para as entidades e grupos que, originalmente, compuseram o Fórum Nacional em Defesa da Escola Pública, na segunda metade dos anos 1980. Com a vitória de forças políticas de centro e direita, foram retiradas, por exemplo, as propostas de educação politécnica e de horas de trabalho pagas pelo empregador para complementação da escolaridade e formação profissional do trabalhador.

Depois de 1989 e da publicação do livro O fim da história de Francis Fukuyama (1992) e dos textos de Claus Offe (entre outros, 1989) e, principalmente, quando as consequências do neoliberalismo e da financeirização da economia se tornaram mais compreensíveis na vida do país, a discussão da centralidade do trabalho monopolizou a atenção dos pesquisadores. Ela punha em cheque o valor do trabalho na produção da existência humana, a própria centralidade do trabalho na constituição do GT. Foram especialmente úteis à recuperação marxista do conceito de trabalho em Lukács. ${ }^{13}$

Também monopolizou o interesse dos pesquisadores do campo TE, diante do desmonte do sistema socialista na URSS (1989) e das políticas neoliberais, o "enxugamento" do modelo produtivo, o corte de custos, os programas de

13 Traduzido por Carlos Nelson Coutinho e Leandro Konder nos anos 1960, os livros de Lukács foram somente retomados nos anos 1980, após o fim da Ditadura, a exemplo das aulas de J. Chasin, dos artigos da Revista Ensaio, das coletâneas organizadas por José Paulo Netto e, mais recentemente, com as traduções da Editora Boitempo. 
Issn: $1808-799 X$

ano 13, número $20-2015$

demissões "voluntárias", o desemprego crescente, a desregulamentação das relações de trabalho, a privatização progressiva dos serviços públicos, a ambiguidade das parcerias público-privadas, que deram nova forma à temática empírica do GT. ${ }^{14}$

Um estudo sobre um balanço das pesquisas em educação com foco na qualificação e na reestruturação produtiva, realizado por Eneida Oto Shiroma e Roselane Campos (1997), inclui, entre suas fontes, contribuições do GT TE. Um dos principais destaques temáticos dado pelas autoras, conforme a literatura da época, é à tese da qualificação ou desqualificação sob a emergente "nova" racionalidade do capital. As autoras concluem que, iniciado no debate internacional nos anos 1980, entre sociólogos, o tema chegou aos pesquisadores de trabalho e educação nos anos 1990, em meio à discussão sobre a politécnica e a poli-valência.

Abrindo mão do "otimismo pedagógico" e duvidando da "formação profissional desvinculada de uma sólida educação básica", Shiroma e Campos (ibid., p.29) concluem que "A informalização, o desemprego, o analfabetismo, a exploração do trabalho colocam-se como grandes desafios à requalificação e à formação profissional na atualidade".

Eram provocativas, na época, as medidas econômicas do governo neoliberal de F. H. Cardoso (1994-1998-2002), a nova organização do trabalho sob o modelo japonês, o toyotismo, e a sua convivência com o modelo tayloristafordista, em um país da periferia do capital como o Brasil. A educação profissional passou a ser desenvolvida, considerando as políticas de formação do ponto de vista do Estado, de sua vinculação com os organismos internacionais - Banco Mundial (BM), Banco Interamericano de Desenvolvimento (BID), Comissão

\footnotetext{
14 Algumas discussões revelavam um certo descontentamento como os rumos da "sociologia industrial" dos trabalhos selecionados e reivindicavam a volta do ensino médio à pauta de discussão. Kuenzer, na entrevista que concedeu a Alexandre Bomfim (2006), "lembra o fim do GT de "Ensino Médio". "O GTTE acabou assumindo indiretamente ou em parte a reflexão daquele grupo, principalmente em função da interface com a temática da formação profissional.". Trein (1996), em entrevista, percebe que a questão da "formação/educação profissional" é a principal temática que a Anped - ou melhor, seus participantes - atribui ao GTTE” (p.77).
} 


\section{Trabalhonecessário}

Issn: $1808-799 X$

ano 13, número $20-2015$

Econômica para a América Latina (CEPAL) -, segundo a visão dos empresários ou do movimento sindical (Trein e Ciavatta, op. cit., p.141).

Essa base teórica pautada no materialismo histórico traz consigo outro traço distintivo do GT: a visão política centrada no compromisso com a transformação das formas de exploração e amesquinhamento do ser humano, geradas pela produção e pela sociabilidade do capital. Tem prevalecido, contudo, o diálogo e o confronto com autores que questionam o marxismo ou que trazem contribuições analíticas orientadas para temas emergentes no contexto das transformações do último século, tais como a sociedade de consumo, a comunicação, a subjetividade, a presença da imagem e o ideário pós-moderno" (idem, p.141). Um momento marcante de questionamento das análises marxistas se faz presente "através de Werner Market e seus estudos sobre profissionalização e competências, tendo por base o pensamento da Escola de Frankfurt".

Em trabalho encomendado pelo GT, em 2000, Gaudêncio Frigotto (2001) alerta para alguns problemas trazidos por aqueles novos tempos: uma certa migração de alguns intelectuais para outras posturas e concepções diversas das marxistas; a adoção de novo paradigma científico-neoliberal, pós-estruturalista ou pós-moderno e pós-crítico; a prevalência das teorias conservadoras que naturalizam o capitalismo como única realidade possível. Finalmente, chama a atenção para as características dessa "nova sociabilidade do capital, a crise do trabalho assalariado, a maximização da exploração e o fim de sua capacidade civilizatória" (Frigotto, 2001, pp.21-22).

Os campos empíricos de pesquisa são diversificados: empresas, sindicatos e escolas. Quanto ás fontes, são documentos, entrevistas, observação participante. Diferentes discursos explicitam as concepções empresariais e sindicais de educação básica, como analisa Sonia Maria Rummert (1998).

É um período emblemático do amadurecimento científico-acadêmico do GT no confronto com os temas desafiadores da vida social. Destacamos algumas 


\section{Trabalhonecessário}

Issn: $1808-799 X$

ano 13, número $20-2015$

questões que evidenciam a importância da questão teórica no GT. As autoras observam: um retorno aos clássicos, notadamente, Marx e Lukács; "a noção de um tempo linear, hegemonizado pelo modo de produção capitalista e implícito nas políticas do Banco Mundial" (Leher, 1996, p.11); o balanço "da nova e da velha crise do capital e o labirinto dos referenciais teóricos" (Frigotto, 2001, p.21); a questão das classes sociais (Trópia, 2007); a teoria do capital humano revisitada no discurso empresarial (Silva, 2002), no contexto dos temas vinculados à sociedade: trabalho e educação e os movimentos sociais (Vendramini, 2003); o avanço das posições pragmáticas no pensamento do governo, dos empresários, dos sindicatos e dos organismos internacionais e suas consequências para a educação; a avaliação do PLANFOR e de PNQs estaduais (a exemplo de CÊA, 2004 e Franzoi, 2004).

Trein e Ciavatta (op. cit., p.160) destacam ainda a aproximação do GT com outras áreas do conhecimento, a economia, a história, a sociologia e, em menor proporção, a ciência política e a comunicação. O que, também, nessa nova conjuntura, não era um ponto pacífico no GT, como Bonfim (2006, p.59) registra em depoimentos de participantes que sentiam como "desprestígio da pesquisa que tem como objeto de estudo especificamente a 'educação' em relação às pesquisas em que o objeto tem um caráter mais sociológico, econômico ou filosófico".

Progressivamente, o GT adquire um formato mais competitivo, na medida em que são criadas exigências da avaliação da produção científica dos professores e alunos dos programas de pós-graduação pela CAPES, e da seletividade introduzida pela implantação do Comitê Científico, para avaliação dos trabalhos a serem apresentados, nas reuniões anuais da ANPEd desde a primeira metade dos anos 1990.

\section{A historicidade do percurso do GT Trabalho e Educação}




\section{Trabalhonecessário}

Issn: $1808-799 X$

ano 13, número $20-2015$

Retomamos, neste terceiro tópico de nossa análise sobre o percurso do GT TE, a questão da historicidade na pesquisa em trabalho e educação reivindicada na primeira análise feita sobre o campo. Há quase trinta anos, escreveu Acácia Kuenzer (1987) que, para superar o tratamento genérico das questões, é preciso "compreendê-las em sua situação histórica concreta; neste sentido, a constituição de um corpo teórico para o exame da relação trabalho/educação implica a reconstrução histórica como aspecto fundamental dessa reflexão" (Kuenzer, 1987, p.93, grifos nossos).

No âmbito de um Programa de Intercâmbio de pesquisas, realizado depois do Encontro de pesquisadores, em 1986, o GT realizou quatro reuniões. Sobre a última delas, assim se expressam Eunice Trein e Iracy Picanço (1995, p.88, grifos nossos): "Buscou-se aprofundar as questões teórico-metodológicas, equacionando melhor a articulação Trabalho e Educação, para compreender a historicidade dos fenômenos gerais e particulares envolvidos por essa articulação". Queremos, com essas citações tão antigas, enfatizar que a perspectiva histórica já estava presente, como preocupação, no início do GT. Resta-nos, aqui, refletir sobre o que significa historicidade e como o GT a tem resgatado nos trabalhos apresentados.

$\mathrm{Na}$ discussão sobre a historicidade da pesquisa em educação e seus desafios teórico-metodológicos, no campo trabalho e educação, buscamos contribuir para a história da educação no que concerne aos processos educativos em sua relação com o mundo do trabalho. ${ }^{15}$ Não obstante a grande obra de Marx ser a crítica ao modo de produção capitalista, sua análise não se faz apenas pelo aspecto econômico. Sua teoria considera a economia como parte da vida social, como história da produção da existência humana. Falamos, assim, sobre a vida de homens e mulheres que não apenas trabalham. Eles comem, se reproduzem, vivem em sociedade, se relacionam, constroem laços de amizade e de

${ }^{15}$ Este tema foi, originalmente, desenvolvido em outros trabalhos, particularmente em fóruns de história da educação (entre outros, Ciavatta, 2014).

TrabalhoNecessário - www.uff.br/trabalhonecessario; Ano 13, №20/2015. 


\section{Trabalhonecessário}

Issn: $1808-799 X$

ano 13, número $20-2015$

colaboração ou competição, pertencem a diferentes grupos e classes sociais, têm ideologias, afetos etc. E constroem sua história em espaços-tempos determinados.

Diferente da historia tradicional que registrou a vida humana dando protagonismo aos heróis, aos poderosos, aos grandes feitos, Marx eleva todos os atos da vida humana ao nível do acontecimento. A história é a produção social da existência (Marx, 1979). Esta é sua concepção inovadora de história, tão bem apropriada por muitos historiadores que incorporaram novas abordagens, novos temas, novos objetos, os grandes acontecimentos e os fatos do cotidiano. ${ }^{16}$ Mas os historiadores não marxistas não reconhecem o singular papel de Marx nessa extraordinária inversão do registro da vida humana, incorporando a todos, vencedores e vencidos, como a "história a contrapelo" (Benjamin, 1987), "a história dos de baixo" (Decca, 1984).

O tratamento historicizado dos fenômenos envolve diferentes temporalidades, tanto em relação ao tema de estudo, quanto ao espaço-tempo em que ocorrem os acontecimentos tratados e às questões teóricometodológicas. Ter como fundamento o método da economia política significa considerar os fenômenos na totalidade social de que fazem parte. Assumir a história como produção social da existência, é entendê-la como processo real da vida humana e como método de pesquisa ao nível da representação pelo pensamento, pela escrita da história. Ao considerar as mediações sociais ou processos sociais complexos que constituem a realidade, tanto no nível da sociedade mais ampla, quanto no contexto das escolas, busca-se superar uma visão economicista e reducionista do materialismo histórico.

A relação história e memória desenvolvida por Jorn Rusen (2009) também nos ajuda a compreender a historicidade da pesquisa nas ciências humanas $e$ sociais e em educação, e a imperiosa relação com a questão do tempo, destacada pelo autor: "A memória torna o passado significativo, o mantém vivo e

${ }^{16}$ Referimo-nos, especialmente, à École des Annales e seus desdobramentos (entre outros, Burke, 1991)

TrabalhoNecessário - www.uff.br/trabalhonecessario; Ano 13, № 20/2015. 


\section{Trabalhonecessário}

Issn: $1808-799 X$

ano 13 , número $20-2015$

o torna uma parte essencial da orientação cultural da vida presente". A história é uma forma elaborada de memória que vai além dos limites da vida individual. $\mathrm{O}$ passado é rememorado em uma unidade de tempo que se abre para o futuro e permite aos sujeitos sociais uma interpretação das mudanças "para ajustar os movimentos temporais de suas próprias vidas" (ibid., p.164).

Rusen distingue memória histórica e consciência histórica. São conceitos que abrangem o mesmo espaço-tempo dos acontecimentos, mas que são tematizados de modo diferente. "A memória está cravada no presente, a consciência histórica abre essa relação ao futuro" (ibidem, p.165).

Marx (1979) trata da consciência no contexto social em que o ser humano produz a vida e produz a história: "Não é a consciência que determina a vida, mas a vida que determina a consciência". O autor apresenta um permanente confronto com posições idealistas: "A produção de ideias, de representações, da consciência, está, de início, diretamente entrelaçada com a atividade material e com o intercâmbio material dos homens, com a linguagem da vida real" (ibidem, p.36).

Entendemos que a pesquisa sobre Trabalho e Educação, além de desvelar a contradição capital e trabalho, deve se ocupar das diversas manifestações da vida humana: as condições de vida e de trabalho, as diversas formas de sociabilidade (política, religiosa, artística etc.), os múltiplos aspectos que concorrem para manifestar sua historicidade. Se quisermos reconstruir a história vivida pelos sujeitos sociais, ao nível do pensamento, devemos fazer apelo à teoria, às categorias que nos ajudam a ordenar o caos dos acontecimentos e apreciá-los sob uma nova luz, como conceitos, como "síntese de múltiplas determinações" (Marx, 1977, p.229), sem perder o elo de sua historicidade em espaços-tempos determinados.

Quando falamos em aproximação da realidade através da reconstrução histórica, duas questões preliminares estão postas: primeiro, recusamos todo dogmatismo e as concepções evolucionistas da história; segundo, recusamos 


\section{Trabalhonecessário}

Issn: 1808 - 799X

ano 13 , número $20-2015$

toda visão cética e fragmentada do mundo e o relativismo como ponto de partida. Aos sistemas explicativos fechados ou funcionais, a uma visão fragmentada da realidade, propomos a busca das articulações que explicam os nexos e significados do real e levam à construção de totalidades sociais, relativas a determinados objetos de estudo. Neste sentido, a totalidade social, reconstruída ao nível do pensamento, não é uma racionalização ou modelo explicativo, mas um conjunto dinâmico de relações que passam, necessariamente, pela ação de sujeitos sociais. Não sendo apenas uma concepção mental, o conceito de totalidade social tem um referente histórico, material, social, moral ou afetivo de acordo com as relações, das mediações ou os processos sociais complexos articulados, que constituem determinada totalidade. Consequentemente, as totalidades são tão heterogêneas e tão diversificadas quanto os aspectos da realidade (Ciavatta, 2001, pp.132-133).

Compreender a história como processo não é apenas uma questão acadêmica ou científica, mas também política, como é a própria questão do conhecimento e da ciência (Cardoso, 1988). A história dos povos mostra que as diferentes concepções e os diferentes relatos que constituem sua história têm, implícita ou explicitamente, posições político-ideológicas de exaltação, de defesa ou de condenação a homens, ações e acontecimentos, atos esses que não estão confinados ao passado. Isto porque os relatos não são apenas narrativas cronológicas ou lineares, histórias objetivas ou versões subjetivas do passado (Ciavatta, 2009).

$\mathrm{Na}$ área trabalho e educação, a produção historiográfica é restrita a alguns grandes trabalhos, livros e artigos, produtos de pesquisas, teses, dissertações. Predomina, nos estudos, a crítica à economia política. Distingue-os ainda a pouca frequência às fontes arquivísticas e à consideração das questões do tempo e do espaço. ${ }^{17} \mathrm{Em}$ parte, talvez, deva-se à sensibilidade dos jovens às urgências das

17 De modo preliminar e incompleto, citamos apenas alguns trabalhos que utilizam também fontes documentais primárias e/ou documentação arquivística (a exemplo de Fonseca, 1986; Cunha,

TrabalhoNecessário - www.uff.br/trabalhonecessario; Ano 13, № 20/2015. 


\section{Trabalhonecessário}

Issn: $1808-799 X$

ano 13 , número $20-2015$

questões do presente que envolvem o capital e a sobre-exploração do trabalho, em sociedades desiguais como a brasileira, e à dívida secular do país para com a educação básica de toda a população, destinada à preparação funcional ao trabalho. Em parte, talvez, à carência de formação, de recursos e de tempo para a pesquisa documental nos arquivos e seus fascinantes labirintos. Ou ainda, porque, à exceção de poucos, raros são os historiadores que se dedicam ao estudo da educação e, consequentemente, estudam o trabalho em suas diversas formas e temporalidades, mas não a relação entre o mundo do trabalho e a educação ou a escola. ${ }^{18} \mathrm{~A}$ história da educação profissional não parece ser, no Brasil, uma área nobre, mesmo entre historiadores da educação que, salvo importantes exceções, soem não se ocupar dela.

Com exceção às declarações de princípio dos documentos iniciais, já mencionados sobre a historicidade e a reconstrução histórica da relação trabalho e educação, revindicada nos primeiros estudos apresentados anteriormente, (Kuenzer, 1987; Trein; Picanço, 1995), os trabalhos seguintes confirmam nossa hipótese sobre os poucos estudos elaborados sob o referencial marxista a partir da história como produção social da existência e como método de estudo da realidade. Mas a questão não está ausente. Trein e Ciavatta (2003), em termos introdutórios, reafirmam a importância da história (ibid., p.140) e, entre as questões mais gerais, a crítica radical ao ideário neoliberal e à ideia do "fim da história" (ibid., p.159) que foram objeto de muitas discussões no GT. Na análise do percurso do GT no período 2002 a 2007, realizada pelas autoras (Trein e Ciavatta, 2009), há uma incidência maior do tema: um trabalho apresentado no GT e dois minicursos com fontes documentais de época (Nosella e Buffa, 1997; Ciavatta, 1998; Moraes e Ciavatta, 1999).

2000a; 2000b; 2000c; Machado, 1982; Ciavatta Franco, 1990; 1993; 2002, 2007; Manfredi, 2002; Moraes, 2003; Oliveira, 2003; Lima, 2007; 2009).

18 O historiador Francisco Falcon (2006) chama a atenção para este fato. Da mesma forma, observamos que o livro Domínios da história, organizado por dois insignes historiadores - um marxista, Ciro Flamarion Cardoso, e outro não marxista, Ronaldo Vainfas (1997) -, trata, em 19 capítulos, de muitas temáticas (econômica, das ideias, cultural, da sexualidade, política etc.), mas não contempla a história da educação.

TrabalhoNecessário - www.uff.br/trabalhonecessario; Ano 13, № 20/2015. 


\section{Trabalhonecessário}

Issn: 1808 - 799X

ano 13 , número $20-2015$

Predominam no GT os trabalhos com fontes documentais mais atuais (leis, políticas e programas governamentais em curso, instituições escolares, organizações sindicais, movimentos sociais). O que conduz a outra questão ainda não suficientemente apropriada e discutida pelo GT, a história do tempo presente. ${ }^{19}$ Há algumas interpretações equivocadas da história do presente, baseadas na leitura factual e imediatista dos fenômenos isolados de seu contexto histórico, a contaminação com a ideia de presentismo, no sentido de que a vida é vivida como um presente permanente.

Há diversas vertentes de aproximação. No caso do presentismo, uma delas são os impactos das grandes transformações do século XX. Outra vertente está nos estudos sobre a juventude, a ideia de uma juventude presentista. A ideia do presentismo afeta a compreensão do tempo que se torna presente, sem memória do passado e sem perspectiva de futuro. A aceleração do tempo pelas tecnologias de comunicação (internet e meios de transporte) tem imprimido um ritmo mais rápido à produção e às relações entre as pessoas. Descarta-se o passado cada vez mais rapidamente, perde-se a visão da totalidade social que constitui os acontecimentos, há uma ruptura do equilíbrio entre o ritmo da vida e as exigências do mundo exterior. No contraponto deste fato está o esquecimento, o apagamento da memória tem sido um tema tratado pelos historiadores, a exemplo de Pierre Nora (1984).

Mas historiadores renomados defendem que a história do presente tem as mesmas exigências de todas as concepções de história. A história do tempo presente diz respeito à concepção do tempo passado, presente e futuro e à possibilidade de conhecimento de cada uma destas temporalidades. Eric J. Hobsbawn (publicado em 1995, no Brasil, e em 1994, na Europa) teria sido o primeiro historiador marxista a chamar a atenção para a forma como a juventude vive uma espécie de presente contínuo.

\footnotetext{
${ }^{19}$ Esta reflexão tem por base (Ciavatta, 2013).
}

TrabalhoNecessário - www.uff.br/trabalhonecessario; Ano 13, № 20/2015. 


\section{Trabalhonecessário}

Issn: 1808 - 799X

ano 13 , número $20-2015$

Recolhemos seus argumentos que trazem a marca da cultura histórica, legitimidade científica e honestidade na identificação dos limites do historiador, que caracterizam sua obra. Hobsbawn começa questionando seu próprio trabalho de historiador, porque seu tempo de vida coincide, na maior parte do tempo, com os fatos de que vai tratar, o que chamou de breve século $\mathrm{XX}$, particularmente, de 1914, início da Primeira Guerra Mundial, a 1989, data do desmonte da União Soviética. Confessa que desconhece a literatura acadêmica publicada sobre 0 período e as fontes primárias acumuladas por muitos historiadores. Considera seu conhecimento, sobre o tema, "precário e irregular", e aventa que isto o leva a ignorar inúmeras questões polêmicas (ibid.).

Depois, expõe outros limites de suas fontes, o fato de ter recorrido "ao conhecimento, às memórias e opiniões acumulados por uma pessoa que viveu como 'observador participante'”, e que, mesmo sendo "um viajante de olhos abertos", conhecendo pessoas e lugares, tendo entrevistado presidentes, "estadistas e protagonistas da história", esteve com pessoas que "falam para registro público". Além disso, suas fontes são "informações obtidas junto a colegas, estudantes" e outros interlocutores da elaboração dos temas, além da leitura de trabalhos e acompanhamento de debates.

Hobsbawn lança a questão sobre os entraves a escrever uma história do presente, mas realiza um trabalho desta natureza, expondo-se, naturalmente, à crítica. O que é coerente com a entrevista que concedeu em sua vinda ao Brasil em 2003, ao participar da Feira Literária Internacional de Parati (FLIP) no Rio de Janeiro: "Sua concepção é que todo estudioso de história, qualquer que seja seu assunto, ao mesmo tempo que investiga o passado, está 'pensando e expressando opiniões a respeito do presente e suas questões e falando a respeito delas'" (Gebara, 2003).

\section{Considerações finais}




\section{Trabalhonecessário}

Issn: $1808-799 X$

ano 13 , número $20-2015$

Este texto buscou traçar as linhas gerais do percurso do GT Trabalho e Educação a partir de três categorias gerais que balizam os estudos de base marxista: pensamento crítico, trabalho e educação e historicidade. Nos termos de um trabalho de metateoria, nossas fontes de análise foram trabalhos produzidos em diversas épocas do GT, por alguns de seus ativos participantes, sobre os textos apresentados e discutidos no GT, nas Reuniões Anuais da ANPEd.

Em mais de trinta anos de existência, o GT TE pautou-se, basicamente, pelo referencial marxista, com base na crítica à economia política e no compromisso com a sociedade brasileira, particularmente, com seu objeto de estudos, a relação entre o trabalho e a educação. $O$ tratamento do tema trabalho e educação, tanto no campo teórico como nas suas manifestações empíricas, situam-no dentro do que se consagrou, não obstante alguma imprecisão do conceito, como pensamento crítico, entre intelectuais da América Latina.

Embora a concepção marxista da história, como produção social da existência, não seja explícita na grande maioria dos trabalhos apresentados e discutidos no GT e/ou publicados em artigos e livros, a historicidade insinua-se nos trabalhos que contemplam o espaço-tempo de vida dos sujeitos das pesquisas.

\section{Referências bibliográficas}

ALTAMIRANO, Carlos et al. Respuesta de Carlos Altamirano. Encuesta sobre el pensamiento crítico en América Latina. Crítica y Emancipación, Revista Latinoamericana de Ciencias Sociales, ano 1, n. ํㅡㄹ 2, pp.14-15, Primer semestre 2009.

BENJAMIN, Walter. Obras escolhidas. Magia e técnica, arte e política. 3a․ ed. São Paulo: Brasiliense, 1987.

BOMFIM, Alexandre M. do. Desvendando a área Trabalho e Educação: estudo sobre a produção e os produtores do GT Trabalho e Educação da ANPEd. Rio de Janeiro, 2006. Tese (Doutorado em Educação) - Pontifícia Universidade Católica do Rio de Janeiro, 2006. 


\section{Trabalhonecessário}

Issn: 1808 - 799X

ano 13 , número $20-2015$

BRAUDEL. Ferdinand. A longa duração. In: História e ciências sociais.

Lisboa, Presença, 1982.

BURKE, Peter. A Escola dos Annales. São Paulo: UNESP, 1991.

CARDOSO, Ciro F. Ensaios racionalistas. Rio de Janeiro: Campus, 1988.

CARDOSO, Ciro F. e VAINFAS, Ronaldo. Domínios da história. Ensaios de teoria e metodologia. Rio de Janeiro: Campus, 1997.

CÊA, Georgia Sobreira dos S. A qualificação profissional como instrumento de regulação social: do Planfor ao PNQ. Trabalho apresentado na 27ํㅡ Reunião Anual da Anped. CD-ROM, 2004.

CIAVATTA FRANCO, Maria. A Escola do Trabalho. História e Imagens. Niterói, 1993. Tese (Titular em Trabalho e Educação). Universidade Federal Fluminense, Niterói: UFF, 1993.

CIAVATTA FRANCO, Maria. História e historiografia em trabalho e educação. In: Encontro de Estudos e Pesquisas em História, Trabalho e Educação, 2007b, Campinas. Unicamp: Grupo de Estudos e Pesquisas HISTEDBR, 3 a 5 set. 2007. (Impresso).

CIAVATTA FRANCO, Maria. Formação profissional para o trabalho incerto: um estudo comparativo Brasil, México e Itália. In: FRIGOTTO, Gaudêncio (Org.). Educação e crise do trabalho: perspectivas de final de século. Petrópolis: Vozes, 1998.

CIAVATTA FRANCO, Maria. Imagens do mundo do trabalho: a fotografia como fonte histórica. Minicurso. In: REUNIÃO ANUAL DA ANPED - Conhecimento e poder: em defesa da universidade pública, 21, 1998, Caxambu. Programa e resumos.

CIAVATTA FRANCO, Maria. O trabalho como princípio educativo. Uma investigação teórico-metodológica (1930-1960), 1990. Tese (Doutorado em Educação) - Pontifícia Universidade Católica, Rio de Janeiro, 1990.

CIAVATTA, Maria. (coord.). Memória e temporalidades do trabalho e da educação. Rio de Janeiro: Lamparina / FAPERJ, 2007.

CIAVATTA, Maria. O conhecimento histórico e a questão teórico-metodológica das mediações. In: . e FRIGOTTO, Gaudêncio. Teoria e educação no labirinto do capital. São Paulo: Vozes, 2001.

CIAVATTA, Maria. A história do presente - Uma opção teórica marxista para a pesquisa em trabalho e educação? Anais. Seminário de Produção Científica do Grupo THESE, Rio de Janeiro, 9 a 11 de dezembro de 2013. No prelo. (Impresso e Digital).

CIAVATTA, Maria. A historicidade da pesquisa em educação. XI CHIELA, Toluca, México, 6 a 8 de maio de 2014. (Impresso e Digital).

CIAVATTA, Maria. A historiografia em Trabalho e Educação e o Pensamento Crítico. Como se escreve a história da educação profissional. Projeto de Pesquisa (CNPq, 2013-2018). Rio de Janeiro, 2012 (Impresso e digital).

CIAVATTA, Maria. e CASTIGLIONI, Paulo. O Rio dos Trabalhadores. Vídeo (20’). Niterói: Neddate/UFF, 2001. 


\section{Trabalhonecessário}

Issn: 1808 - 799X

ano 13 , número $20-2015$

CIAVATTA, Maria. Mediações históricas de relação trabalho e educação. Gênese da disputa na formação dos trabalhadores (1930-1960). Rio de Janeiro: Lamparina / CNPq / FAPERJ, 2009.

CIAVATTA, Maria. O mundo do trabalho em imagens. A fotografia como fonte histórica (Rio de Janeiro, 1900-1930). Rio de Janeiro: DP \& A, 2002.

CIAVATTA, Maria; SILVEIRA, Zuleide S. da. Celso Suckow da Fonseca. Recife: FJN/Editora Massangana, 2010.

CUNHA, Luiz Antônio. O ensino de ofícios artesanais e manufatureiros no Brasil escravocrata. São Paulo: UNESP; Brasília: FLACSO, 2000a.

CUNHA, Luiz Antônio. O ensino de ofícios nos primórdios da industrialização. São Paulo: UNESP; Brasília: FLACSO, 2000b.

CUNHA, Luiz Antônio. O ensino profissional na irradiação do industrialismo. São Paulo: UNESP; Brasília: FLACSO, 2000c.

DECCA, Edgar de. 1930. O silêncio dos vencidos. São Paulo: Brasiliense, 1984.

FALCON, Francisco J. C. História cultural e história da educação. Revista Brasileira de Educação, vol. 11, n.ำ 32, pp.328-339, maio/ago. 2006.

FONSECA, Celso S. da. História do Ensino Industrial no Brasil. 5 Vol. Rio de Janeiro: SENAI/DN, 1986.

FRANZOI, Naira L. Da profissão como profissão de fé ao "mercado em constante mutação": trajetórias e profissionalização dos alunos do plano estadual de qualificação do Rio Grande do Sul (PEQ-RS). Trabalho apresentado na $27^{\text {a }}$ Reunião Anual da Anped. CD-ROM, 2004.

FRIGOTTO, Gaudêncio. A nova e a velha faces da crise do capital e o labirinto dos referenciais teóricos. In: e CIAVATTA, Maria (orgs.). Teoria e educação no labirinto do capital. Petrópolis: Vozes, 2001.

FUKUYAMA, Francis. O fim da história e o último homem. Rio de Janeiro: Rocco, 1992.

GEBARA, Alexandre. A história escreve-se do presente. Biografia. Ciência e Cultura, vol.55, n.ำ 4, São Paulo, out./dez. 2003.

HOBSBAWN, Eric J. Era dos extremos: o breve século XX. São Paulo: Companhia das Letras, 1995.

KOHAN, Néstor. Pensamiento crítico y el debate por las ciências sociales, In: BEIGEL, Fernanda et al. Crítica y teoria en el pensamiento social latinoamericano. Buenos Aires: Clacso, 2006.

KUENZER, Acácia Zeneida. Educação e trabalho no Brasil; o estado da questão. Brasília: Inep/MEC, 1987.

KUENZER, Acácia. Desafios teórico-metodológicos da relação trabalho-educação e o papel social da escola. In: FRIGOTTO, Gaudêncio. Educação e crise do trabalho: perspectivas de final de século. São Paulo: Cortez, 1998.

LEHER, Roberto. Educação e tempo desiguais: reconstrução da problemática trabalho e educação. In: REUNIÃO ANUAL DA ANPED - A política de educação no Brasil: globalização e exclusão social, 19, 1996, Caxambu. Programa. 


\section{Trabalhonecessário}

Issn: 1808 - 799X

ano 13 , número $20-2015$

LIMA, Marcelo. A história de educação profissional. Os passos e descompassos históricos do SENAI-ES com os paradigmas da produção industrial no Espírito Santo 1948/1999. Vitória: O Autor, 2009.

LIMA, Marcelo. O desenvolvimento histórico do tempo socialmente necessário para a formação profissional: do modelo correcional-assistencialista das Escolas de Aprendizes Artífices ao modelo tecnológico-fragmentário dos CEFETs. Vitória: Autor, 2010.

LUCKÁCS, Gyorgy. As bases ontológicas do pensamento e da atividade do homem. Temas de Ciências Humanas, São Paulo, (4): 1-18, 1978.

MACHADO, L. R. S. Educação e divisão social do trabalho: contribuição para o estudo do ensino técnico industrial brasileiro. São Paulo: Cortez, 1982.

MACHADO, Lucília. Trabalho-Educação como princípio de investigação. Revista do NETE, UFMG, vol. 14, n. 2, pp.127-136, jul. dez. 2005.

MANACORDA, Mário. O principio educativo em Gramsci. Porto Alegre: Artes Médicas, 1990.

MANFREDI, Sílvia M. Educação Profissional no Brasil. São Paulo: Cortez, 2002.

MARSHALL, Thomas H. Cidadania, classe social e status. Rio de Janeiro: Zahar, 1967.

MARX, Karl. Contribuição à crítica da economia política. São Paulo: Estampa, 1977.

MARX, Karl; ENGELS, Friedrich. A ideologia alemã (Feuerbach). São Paulo: Ciências Humanas, 1979.

MORAES, Carmen Sylvia V. de. A socialização da força de trabalho: Instrução popular e qualificação profissional no Estado de São Paulo (1873-1934). Bauru, SP: EDUSC, 2003.

MORAES, Carmen Sylvia V. de e FRANCO, Maria Ciavatta. Trabalho e Educação na sociedade brasileira: uma perspectiva histórica. Minicurso. In: REUNIÃO ANUAL DA ANPED - Educação, crise e mudança: tensões entre a pesquisa e a política, Programa e resumos, 1999

NORA, Pierre. Entre mémoire et histoire: la problematique des lieux. In: Les lieux de memoire: la République. Paris: Gallimard, 1984.

NOSELLA, Paolo e BUFFA, Ester. Artes liberais e mecânicas: a difícil integração. In: ANPEd - 20 ${ }^{\text {a }}$ Reunião Anual - Educação, crise e mudança: tensões entre a pesquisa e a política. Programa e resumos. Caxambu/MG, 23 a 25 de setembro de 1997.

OFFE, Claus. Trabalho como categoria sociológica fundamental? In:

(org.). Trabalho \& Sociedade. Problemas estruturais e perspectivas para a sociedade do trabalho. Volume I - A crise. Rio de Janeiro: Tempo Brasileiro, 1989.

OLIVEIRA, Milton Ramon Pires de. Formar Cidadãos úteis: os patronatos agrícolase a infância pobre na Primeira República. Bragança Paulista: EDUSF, 2003. 


\section{Trabalhonecessário}

Issn: $1808-799 X$

ano 13 , número $20-2015$

RUMMERT, Sonia M., (1998). Capital e trabalho: convergências e divergências quanto à educação básica. Trabalho apresentado na $21^{\text {a }}$ Reunião Anual da ANPEd. In: ANPEd 25 anos, CD-ROM histórico, 2002.

RUSEN, Jorn. Com dar sentido ao passado: questões relevantes de meta-história. História da historiografia, (2), março, pp.163-209, 2009.

SADER, Emir. Apresentação. Cadernos de Pensamento crítico latino-americano. Vol. 1. 1a.ed. São Paulo: Expressão Popular/ CLACSO, 2008.

SADER, Emir. Encuesta sobre el pensamiento crítico em América Latina. Crítica y Emancipación, Revista Latinoamericana de Ciencias Sociales, ano 1, n. ${ }^{\circ}$ 2, pp.1213, Primer semestre 2009.

SAVIANI, Dermeval. Sobre a concepção de politecnia. Rio de Janeiro: MS/FIOCRUZ, 1989.

SHIROMA, Eneida e CAMPOS, Roselane F. Qualificação e reestruturação produtiva: um balanço das pesquisas em educação. Educação \& Sociedade, Campinas, CEDES, n.․ 61, pp.13-35, dez 1997.

SILVA, Maria Vieira. O ethos empresarial na educação escolar: novos dispositivos, novas subjetividades. Trabalho \& Crítica, Anuário do GT Trabalho e Educação, ANPEd/UFSC, n.ำ 3, pp.183-199, 2002.

TORRES-RIVAS, Edelberto. Respuesta de Edelberto Torres-Rivas. Encuesta sobre el pensamiento crítico em América Latina. Crítica y Emancipación, Revista Latinoamericana de Ciencias Sociales, ano 1, n.ำ 2, pp.20-22, Primer semestre 2009a.

TORRES-RIVAS, Edelberto. Dependência, marxismo, revolución y democracia. La perspectiva desde la periferia. Entrevista a Jorge Rovira Mas et al. Crítica y Emancipación, Revista Latinoamericana de Ciencias Sociales, ano 1, n.ำ 2, pp.4776, Primer semestre 2009b.

TREIN, Eunice. Entrevista. Revista do Nete, n.ำ 0, pp.32-40, jul.-dez. 1996.

TREIN, Eunice e CIAVATTA, Maria. O teórico e empírico do GT Trabalho e Educação: uma análise para debate. Revista Brasileira de Educação, n. 24, pp.140-164, set./out./nov./dez. 2003.

TREIN, Eunice e CIAVATTA, Maria. A historicidade do percurso do GT Trabalho e Educação; uma análise para debate. Trabalho, Educação e Saúde, vol. 7, Suplemento 1, pp.15-50, 2009.

TREIN, Eunice e PICANÇO, Iracy S. O GT Trabalho e Educação. In: Histórico dos grupos de trabalho. Belo Horizonte: Anped, 1995.

TRÓPIA, Patrícia Vieira. A inserção dos assalariados não-manuais: um debate com a bibliografia marxista sobre a classe média. Trabalho apresentado na $30^{\underline{a}}$ Reunião Anual da Anped. CD-ROM, 2007

VENDRAMINI, Célia Regina. Assentamentos do MST e identidade coletiva. Trabalho apresentado na 26ㄹ Reunião Anual da Anped. CD-ROM, 2003.

Recebido em 10 de outubro de 2014 Aprovado em 20 de dezembro de 2014 